\title{
LAS GANANCIAS OBTENIDAS POR PERSONAS JURIDICAS NO DOMICILIADAS CUANDO VENDEN ACCIONES
}

Luis Hernández Berenguel

Desde que entró en vigencia el antiguo régimen de impuesto a la renta aprobado por el Decreto Supremo $N^{\circ} 287-68-\mathrm{HC}$, las opiniones se dividieron respecto a si estaban o no gravadas con dicho tributo las ganancias obtenidas por personas jurídicas no domiciliadas, cuando eran obtenidas por la venta de acciones que formaban parte de su activo y que habian sido emitidas por sociedades anónimas o sociedades en comandita por acciones constituidas en el país. Como se verá más adelante, el Tribunal Fiscal sentó jurisprudencia resolviendo que dichas ganancias estaban gravadas.

La divergencia de opiniones en torno al mismo asunto se mantiene desde la vigencia del nuevo régimen de impuesto a la renta aprobado por el Decreto Legislativo $\mathrm{N}^{\circ} 200$, y que actualmente se encuentra regulado por el Texto Unico Ordenado, aprobado por el Decreto Supremo No $300-85-E F$ de 12 de julio de 1985 , que llamaré "TUO", modificado por los Decretos Legislativos Nos. 362, 399 y 412 . Este régimen está reglamentado por los Decretos $\mathrm{Su}$ premos Nos. 529-85-EF de 27 de diciembre de 1985 y 325-86-EF de 19 de setiembre de 1986, a los que citaré bajo la denominación de "Reglamento", no habiéndose expedido aún las normas reglamentarias que procede dictar por la dación del Decreto Legislativo $\mathrm{N}^{\circ} 399$.

El presente trabajo pretende efectuar un análisis estrictamente técnico del tema en función de las normas actualmente vigentes, y sólo referencialmente se hará mención de la jurisprudencia que recayó cuando estaba en vigor el régimen del Decreto Supremo $\mathrm{N}^{\circ}$ 287-68-HC. Para este efecto, considero necesario dividir el tema en las siguientes partes: 1) Campo de aplicación del impuesto a la renta; 2) Rentas de fuente peruana; 3 ) Jurisprudencia aplicable al régimen anterior; 4) Conclusiones. 
El Capítulo I del TUO tiene como denominación "Ambito de Aplicación". Es decir que dicho capítulo tiene por objeto establecer los límites del tributo o el campo de aplicación del mismo. Dicho de otra manera, el objeto del tributo, de forma tal que todo aquello que no está comprendido dentro de los alcances del ref erido capitulo queda inafecto al tributo, puesto que en la realidad ello no implica la ocurrencia o realización de los presupuestos de hecho o hipótesis de incidencia tributaria previstos por la ley para que nazca la obligación tributaria.

La denominación del capítulo mencionado responde plenamente al contenido del mismo. En efecto, el artículo $1^{\circ}$ se encarga de corroborarlo al señalar que el impuesto a la renta grava: a) Las rentas que provengan del capital, del trabajo y de la aplicación conjunta de ambos factores, entendiéndose como tales aquéllas que provengan de una fuente durable y susceptible de generar ingresos periódicos; $y$, b) Las ganancias y beneficios considerados en los artículos siguientes del Capítulo 1 (artículos $2^{\circ}$ y $3^{\circ}$, puesto que los artículos $4^{\circ}$ y $5^{\circ}$ se limitan a establecer presunciones de habitualidad y a definir lo que es "enajenación" para efectos del impuesto, respectivamente).

El articulo $1^{\prime}$ claramente está fijando el siguiente concepto: el impuesto a la renta únicamente se aplica sobre los ingresos que constituyen renta según la teoría del rédito-producto y sobre las ganancias y beneficios que, no respondiendo al concepto de renta de la citada teoría, se encuentran expresamente gravados por los artículos $2^{\circ}$ y $3^{\circ}$. Cualquier otro ingreso está inafecto al impuesto, encontrándose fuera del campo o ámbito de aplicación del tributo, porque se trataría de un ingreso no previsto como presupuesto de hecho cuya realización genera la obligación tributaria correspondiente. En otras palabras, y es preciso insistir en este concepto, todo otro ingreso que obtenga una persona no implica la realización del hecho imponible que, con arreglo a lo dispuesto en el artículo $23^{\circ}$ del Código Tributario, hace nacer la obligación referida en este caso al impuesto a la renta. 
Garcia Belsunce (1) define el concepto de renta, según la teoría del rédito-producto, como "la riqueza nueva material (periódica o susceptible de serlo) que fluye de una fuente productiva durable y que se expresa en términos monetarios". La teoría económica, admite que el rédito pueda ser inmaterial, "representado por los servicios derivados del capital o los goces y satisfacciones que resultan del uso de los bienes" (2), a diferencia de la doctrina fiscal.

Dentro de la referida teoría, la renta necesariamente comprende únicamente a las cosas que pueden contarse o medirse con exactitud, ya sea que estén expresadas en dinero o que se expresen en bienes susceptibles de valuación monetaria. Nuestra legislación, en el citado inciso a), considera como fuente al capital, al trabajo y a la empresa, entendida esta últina como la combinación del capital $y$ del trabajo. A su vez, cuando dicho inciso requiere la existencia de una fuente "durable", descarta la existencia de renta si la fuente desaparece para su propietario con la obtención del ingreso y, por lo tanto, la ganancia obtenida por la enajenación de la fuente productora no puede ser reputada como renta bajo la teoría del rédito-producto, siendo éste justamente el caso de la ganancia que obtiene una persona jurídica no domiciliada en el pais, que es propietaria de acciones emitidas por una sociedad constituida en el país, sea esta última una sociedad anónima o una sociedad en comandita por acciones, cuando esa ganancia proviene de la venta de dichas acciones.

Bastaria lo antes expuesto, para descartar que la citada ganancia sea renta gravada en el Perú por a plicación del inciso a) del artículo $1^{\circ}$ del TUO. De todas formas, conviene completar la definición de renta usada en dicho inciso haciendo alusión a la expresión "susceptible de generar ingresos periódicos", que coincide con la definición de García Belsunce, en cuanto éste habla de que la riqueza debe ser periódica o susceptible de serlo.

El concepto usado por el inciso a) únicamente difiere del que

(1) GARCIA BELSUNCE, Horacio A., El Concepto de Rédito en la Doctrina y en el Derecho Tributario (Ediciones Depalma, Buenos Aires, 1967).

(2) GARCLA BELSUNCE, Horacio A., op. cit. 
recoge el mencionado autor, en que la ley peruana no utiliza la palabra "productiva", que alude al concepto de habilitación o explotación de la fuente, y que sería recomendable incorporar.

Al aludir al concepto de "renta producida", Cosciani (3) señala que "Se comprende, asi, que las legislaciones que acogen este concepto generalmente pongan como condición para el gravamen que la renta provenga de una riqueza nueva, atribuible a una fuente duradera y productiva (como el trabajo o el capital), tenga un carácter periódico o, al menos, susceptible de repetibilidad y, a menudo, esta nueva riqueza es gravable no cuando se produce sino cuando se realiza, es decir, cuando existe una separación de la fuente productiva (venta, permuta, etc.)". Recoge Cosciani, como requisito indispensable para que se configure la renta, bajo la teoría del rédito-producto, que la fuente sea duradera y que la riqueza sea susceptible de repetirse, lo que no se dá cuando la fuente productiva es transferida a un tercero.

Sin embargo, como ya se ha visto, nuestro impuesto a la renta no está exclusivamente basado en el concepto de renta de la teoría del rédito-producto, porque además considera, en el inciso b) del artículo $1^{\circ}$ del TUO, a las ganancias y beneficios expresamente incluidos en el Capítulo 1. En tal capítulo sólo hay que analizar los artículos $2^{\circ}$ y $3^{\circ}$.

El artículo $2^{\circ}$ tiene tres incisos, referidos a las ganancias y beneficios que provienen de: a) la adjudicación de bienes al socio, por retiro de éste o por disolución parcial o total de cualquier sociedad; b) la enajenación de bienes obtenidos por el titular de una empresa, como consecuencia del cese de las actividades desarrolladas por esa empresa, siempre que la enajenación se produzca dentro de cierto plazo; c) determinadas indemnizaciones. Ninguna de estas hipótesis podría ser aplicada para gravar las ganancias obtenidas por personas jurídicas no domiciliadas, por la venta de acciones a que se refiere el presente trabajo.

El artículo $3^{\circ}$ contiene tres incisos que es necesario analizar por separado.

(3) COSCIANI, Césare, Ciencia de la Hacienda (Editorial de Derecho Financiero, Editoriales de Derecho Reunidas, Madrid, 1980). 
El inciso a) del artículo $3^{\circ}$ no es aplicable al caso en cuestión, pues se refiere a las regalías que, según la definición contenida en el artículo $27^{\circ}$ del TUO, tal como ha sido modificado por el artículo $4^{\circ}$ del Decreto Legislativo $N^{\circ} 399$, constituyen la contraprestación por: a) el uso o el privilegio de usar derechos de propiedad industrial y derechos de autor de trabajos literarios, artisticos o científicos; $y, b)$ la información relativa a la experiencia industrial, comercial o científica, entendida como "toda trasmisión de conocimientos, secretos o no, de carácter técnico, económico, financiero o de otra índole referidos a actividades comerciales o industriales, con prescindencia de la relación que los conocimientos trasmitidos tengan con la generación de rentas de quienes los reciben y del uso que éstos hagan de ellos". No se trata aquí del uso o el privilegio de usar determinados derechos, ni de la contraprestación por información.

El inciso b) del artículo $3^{\circ}$ contiene ocho numerales, dos de los cuales pueden ser invocados, con fundamento, para gravar las ganancias a que se contrae el presente trabajo, bajo ciertas condiciones, según pasaremos a demostrar. Cabe precisar que todos los numerales consideran como supuesto la enajenación de bienes o derechos.

El numeral 1 se refiere a las ganancias obtenidas por la enajenación de terrenos rústicos o urbanos por el sistema de urbanización o lotización, y no a las que provienen de la enajenación de acciones.

El numeral 2 grava los resultados provenientes de la enajenación de inmuebles, estén o no comprendidos bajo el régimen de propiedad horizontal, siempre que hubieran sido adquiridos o edificados, total o parcialmente, para efectos de la enajenación. No se dice nada sobre la enajenación de acciones.

En el numeral 3 se contempla el caso de ganancias obtenidas por la enajenación de bienes adquiridos en pago de operaciones habituales o para cancelar créditos provenientes de las mismas. Nótese que se incluye a todo tipo de bienes, de forma tal que, en principio, están incluidas las acciones, pero sería necesario que las mismas hubieran sido recibidas en propiedad por la persona juridica no domiciliada en el pais, en pago de operaciones habituales de di- 
cha persona o para cancelar créditos provenientes de dichas operaciones habituales.

Se establece como presupuesto la existencia de operaciones habituales, aún cuando no se indica si ellas deben realizarse en el territorio nacional o, inclusive, fuera de él. De otro lado, es preciso que en pago de esas operaciones habituales o para cancelar créditos provenientes de dichas operaciones, se reciban bienes. En tercer lugar, tales bienes deben ser enajenados, no requiriéndose que tal enajenación sea habitual. En cuarto y último lugar, esa enajenación debe producir una ganancia.

En cuanto al primer requisito, existen dos argumentos que permitirian concluir que las operaciones habituales deben forzosamente realizarse en el territorio nacional. El primer argumento se basa en la norma XII del Título Preliminar del Código Tributario, según la cual "las normas tributarias rigen en todo el territorio nacional, y en sus aguas y aires jurisdiccionales". El argumento deriva del hecho que, si bien las personas jurídicas no domiciliadas deben pagar el impuesto a la renta peruano, esto solamente ocurre cuando obtienen rentas de fuente peruana, según el artículo $6^{\circ}$ del TUO, y éstas se caracterizan por la existencia de un vínculo territorial y, por lo demás, están expresamente señaladas en los artícu$\operatorname{los} 7^{\circ}$ al $12^{\circ}$ del Tuo y no en el Capítulo I del mismo. Ahora bien, es posible que una persona jurídica no domiciliada realice operaciones habituales en el pais, sin que ello necesariamente determine la existencia de una sucursal, agencia o establecimiento permanente en el país de esa persona jurídica no domiciliada.

El segundo requisito también podría ser cumplido, pues la persona jurídica que realiza operaciones habituales en el país sin tener un establecimiento permanente en él, estaría en aptitud de obtener bienes, y entre éstos se incluyen las acciones emitidas por sociedades anónimas o sociedades en comandita por acciones constituidas en el país, en pago de esas operaciones habituales, por mencionar un ejemplo.

Bajo esta hipótesis, se podría cumplir también con el tercer y cuarto requisitos. Vale decir que la persona jurídica no domiciliada, y que no tiene establecimiento permanente en el pais, que ha recibido las acciones en pago de operaciones habituales, vende esas 
acciones, por citar un solo caso de enajenación, y obtiene una ganancia en la venta. Me parece que en este caso, la ganancia quedaría gravada, en virtud del numeral 3 que se viene comentando. Sin embargo, es éste un caso excepcional. Lo normal es que la persona jurídica no domiciliada venda acciones de su propiedad, emitidas por una sociedad constituida en el Perú, sin que realice operaciones habituales en el país o que, realizándolas, no haya recibido tales acciones en pago de operaciones habituales o para cancelar créditos provenientes de las mismas. En todo caso, el presente trabajo tiene por objeto referirse a tales situaciones normales y no a casos excepcionales que son los que encuadrarian en los alcances del numeral 3 en cuestión.

El numeral 4 califica como rentas gravadas los resultados provenientes de la enajenación de "bienes nuebles cuya depreciación admite esta Ley". Empero. las acciones no sufren desgaste ni obsolescencia, ni tienen la calidad de bienes del activo fijo, razón por la cual no pueden ser depreciadas, tal como dice, al respecto, el inciso g) del artículo $40^{\circ}$ del TUO.

El numeral 5 grava los resultados provenientes de la enajenación de derechos de llave, marcas y similares. Evidentemente, las acciones no son derechos de llave ni marcas, ni responden al concepto de "similares" a esos derechos y marcas.

El numeral 6, modificado por el Derecho Legislativo $N^{\circ} 399$, grava los resultados de la enajenación de "bienes de cualquier naturaleza que constituyen activos de personas jurídicas o empresas constituidas en el país, de las empresas unipersonales domiciliadas a que se refiere el tercer párrafo del artículo $13^{\circ}$ o de establecimientos permanentes de empresas constituidas o domiciliadas en el exterior que desarrollen actividades generadoras de rentas de la tercera categoria".

Lo primero que es preciso constatar es que el citado numeral alude a todo tipo de bienes, comprendiendo a las acciones. Tales acciones, obviamente, deben tener la condición de activos propios de quien las está enajenando. Pero, además, el propietario que enajena las acciones no puede ser cualquier persona o entidad, sino solamente uno de aquéllos a quienes expresamente se refiere el numeral 6. Vale decir que el propietario sólo puede ser: a) una perso- 
na juridica constituida en el país, que tiene por tanto la condición de domiciliada en el Perú, según el inciso d) del artículo $7^{\circ} \mathrm{del}$ TUO: b) una empresa constituida en el pais, refiriéndose la norma a quienes son personas juridicas según el derecho común pero no lo son para efectos del impuesto a la renta, que a su vez debe reputarse como empresa domiciliada en el Perú aún cuando no existe norma expresa al respecto; c) una empresa unipersonal domiciliada, comprendida en el tercer párrafo del artículo $13^{\circ}$;) un establecimiento permanente de empresas constituidas o domiciliadas en el exterior, que desarrollen actividades generadoras de rentas de tercera categoría. Como se puede observar, no están comprendidas las personas juridicas no domiciliadas en el Perú que no tienen establecimiento permanente en el país. Conviene recordar que el inciso g) del artículo $13^{\circ}$ del TUO, modificado por el Decreto Legislativo $\mathrm{N}^{\circ} 399$, considera que son personas jurídicas, para efectos del impuesto a la renta, a "las empresas unipersonales, la sociedades y las entidades de cualquier naturaleza, constituidas en el exterior, que en cualquier forma perciben rentas de fuentes peruana".

Bajo el numeral 6 no es posible considerar, por lo tanto, como renta gravada, la ganancia obtenida por una persona jurídica no domiciliada en el Perú, como consecuencia de haber vendido acciones de su propiedad que han sido emitidas por una sociedad constituida en el país.

En virtud del numeral 7 quedan gravados con el impuesto a la renta, los resultados provenientes de la enajenación de negocios y empresas. La norma no se refiere a acciones.

El numeral 8 grava los resultados de la enajenación de denuncios y concesiones, pero no menciona las acciones.

En definitiva, la única norma que, en forma excepcional, podría gravar las ganancias que son objeto del presente trabajo, resulta ser, hasta el momento, el numeral 3 del inciso b) del artículo $3^{\circ}$ del TUO.

$\mathrm{El}$ artículo $3^{\circ}$ tiene un último inciso. El inciso $\mathrm{c}$ ), que grava los resultados de la venta, cambio o disposición habitual de bienes. Concretándonos a la figura de la venta de acciones, la ganancia sólo resultaría gravada en cuanto provenga de venta habitual de bie- 
nes. La persona jurídica no domiciliada tendría que dedicarse en forma habitual a la "venta de acciones". Caben varias preguntas. Qué se entiende por habitualidad? La habitualidad debe reflejarse a través de operaciones realizadas exclusivamente en el Perú o para determinarla se deberian tomar en cuenta las operaciones realizadas tanto en el país como en el extranjero? La habitualidad debe ser definida separadamente, vinculándola solamente a la venta de acciones, o para determinar su existencia se deben tomar en cuenta las otras operaciones de "disposición de bienes"? Puede haber habitualidad cuando se venden, en forma exclusiva, acciones de sociedades que no están constituidas en el pais? Se tratará de dar respuesta a estas interrogantes.

En un trabajo anterior (4), distinguida entre profesión habitual y comercio, considerando en principio que el comercio es una forma de habitualidad referida exclusivamente a la frecuencia, periodicidad o repetición de actos comerciales, en tanto que "profesión habitual" suponía ejercitar con frecuencia, periodicidad o repetición actos civiles o comerciales. Como se señalaba en dicho trabajo, el inciso c) del artículo $3^{\circ}$ del TUO sólo grava los ingresos que responden al concepto de la teoría del "rédito-producto", lo que implica, para el tema en cuestión, que el enajenante ejerza el comercio en la actividad de compra y venta de acciones, hipótesis en la cual las acciones son mercaderías para quien las está vendiendo. Determinar si las acciones son mercaderías no solamente supone verificar la frecuencia, periodicidad o repetición de las operaciones de venta de acciones, sino sobre todo "un análisis del origen de las adquisiciones, del motivo de las mismas, del destino de los bienes adquiridos, $y$ de la vinculación de las adquisiciones con las enajenaciones..." (5). En la presunción de habitualidad que, tratándose de acciones, establece el artículo $4^{\circ}$ del TUO, se exige un número determinado de operaciones de compra y de venta, no computándose las adquisiciones que no son compras ni las enajenaciones que no son ventas, aún cuando presumida la habitualidad que-

(4) HER NANDEZ BERENGUEL, Luis, la Presunción de Habitualidad aplicable a las Personas Naturales en el Impuesto a la Renta (Revista del Instituto Peruano de Derecho Tributario, Vol. No 10 , Industrial Gráfica S.A., Lima, 1986).

HER NANDEZ BER ENGUEL, Luis, op. cit. 
dan gravadas las ganancias que provengan de cualquier operación de enajenación. Sin embargo, la existencia de la presunción no descarta que la habitualidad pueda ser probada en base a la existencia de los otros conceptos que acabo de mencionar.

En otras palabras, prescindiendo por ahora de la presunción de habitualidad contenida en el artículo $4^{\circ}$, habrá habitualidad si el vendedor está vendiendo acciones que para él son mercaderias, lo que presupone que compra acciones para venderlas y que, por lo tanto, ejerce el comercio, haciendo empresa.

De otro lado, creo que para calificar a la persona jurídica no domiciliada como habitual en la venta de acciones, habría que tomar en cuenta no solamente las ventas que efectúa en el Perú sino también las que realiza en el extranjero, pero en función de los criterior anteriormente expuestos. $\mathrm{A}$ su vez, para determinar la habitualidad, podrían incluirse también las compras y ventas de acciones emitidas por sociedades que no están constituidas en el Perú. Empero, una vez determinada la habitualidad. sólo quedarían gravadas en el Perú las ganancias obtenidas por la venta de acciones emitidas por sociedades constituidas en el pais, sin importar el lugar donde se realice la venta, el lugar donde físicamente se encuentren los títulos representantivos de las acciones, el lugar donde se pague el precio por la venta de las acciones, ni la nacionatidad o domicilio del comprador. Esto tendria que ser así por la territorialidad de la ley, que en nuestro impuesto a la renta se expresa. tratándose de personas jurídicas no domiciliadas, gravando únicamente las rentas de fuente peruana que. como se verá en el punto 2 de este trabajo. se caracterizan por la existencia de un vínculo territorial. En materia de acciones. ese vínculo se da cuando la acción vendida ha sido emitida por una sociedad constituida en el territorio nacional.

Por otra parte. para determinar la habitualidad no se debe tomar en consideración cl carácter de comerciante que pueda tener la persona jurídica no domiciliada y que se derive de la realización de operaciones referidas a bienes que no sean acciones, aún cuando tales operaciones revelen que se compran bienes para ser vendidos. La habitualidad debe ser calificada, para efectos de gravar la ganancia obtenida por la venta de acciones emitidas por sociedades constituidas en el pais. en función de las acciones emitidas por todo ti254 
po de sociedades y que han sido compradas para ser vendidas. y en base a los criterios que les confieren la calidad de "mercaderias".

De acuerdo a lo expuesto, no estará gravada en el Perú, con el impuesto a la renta, la ganancia obtenida por una persona jurídica no domiciliada, que provenga de la venta de acciones de su propiedad que han sido emitidas por sociedades constituidas en el Perú, si dicha persona no ha podido ser calificada como habitual en la venta de acciones.

Merece un comentario el artículo $4^{\circ}$. en cuanto establece dos presunciones de habitualidad. Una primera, que no interesa para efectos del presente trabajo, destinada al caso de inmuebles. Una segunda, destinada al caso de acciones, participaciones representativas del capital de sociedades, acciones laborales, bonos y cédulas hipotecarias. Ambas presunciones son relativas, liberando a la Dirección General de Contribuciones, que es el órgano administrador del tributo, de tener que probar la habitualidad. Se desplaza la carga de la prueba a la persona afectada por la presunción, quien podrá demostrar que no es habitual. Si consigue demostrar tal cosa, las ganancias que hubiera obtenido en cualquier operación de enajenación de acciones, incluyendo ventas, no quedarán gravadas por la norma del inciso c) del artículo $3^{\circ}$. Es bueno recordar que el artículo $4^{\circ}$ del TUO no tiene por objeto gravar ingresos no previstos por los artículos anteriores, sino presumir la habitualidad para gravar determinados ingresos que estan afectos a mérito de la norma contenida en el inciso c) del artículo $3^{\circ}$.

De otro lado. las ganancias gravadas por el inciso c) del artículo $3^{\circ}$ del TUO. lo están en razón de que el enajenante es habitual. La habitualidad se presume cuando se dan los supuestos previstos en el artículo $4^{\circ}$. Empero, si no se dan tales supuestos y la presunción resulta inaplicable, cabe siempre la posibilidad de que la Dirección General de Contribuciones pruebe la existencia de la habitualidad, por otros medios.

El artículo $5^{\circ}$ del TUO se limita a definir el concepto de "enajenación". considerando que ella se da en todo acto de disposición por el que se trasmita el dominio a titulo oneroso. Una de las formas de enajenación, y la única que nos interesa para efectos del presente trabajo, es la venta. Pero. como se dijo anteriormente. en virtud del artículo $5^{\circ}$ no se grava ningún ingreso. 
No hay más artículos en el Capítulo I del TUO. Por lo tanto, no existen otros ingresos, distintos a los que contiene dicho capitulo, que estén gravados en el Perú con impuesto a la renta. De manera que, salvo los casos previstos en el numeral 3 del inciso b) del artículo $3^{\circ}$ y en el inciso c) del citado artículo, no están gravadas con el impuesto a la renta peruano, las ganancias obtenidas por personas jurídicas no domiciliadas en el país como consecuencia de la venta de acciones de su propiedad emitidas por sociedades anónimas y por sociedades en comandita por acciones constituidas en el país.

Si se desea gravar dichas ganancias en todos los casos, será necesario modificar el TUO. Como tales ganancias no responden al concepto de renta de la teoría del rédito-producto, habría que gravarlas expresamente. En tal sentido, proviniendo de enajenación de bienes, lo técnico sería agregar al inciso b) del artículo $3^{\circ}$, un nuevo numeral. Es preciso, pues, aprobar el numeral 9, que podría tener la siguiente redacción: "9) Acciones emitidas por sociedades anónimas o en comandita por acciones, cuando el enajenante sea una persona jurídica no domiciliada en el país". Claro está que esta redacción determinará que se graven las ganancias que provengan de todo acto de enajenación, y no solamente de ventas, conforme a la definición del artículo $5^{\circ}$ del TUO.

No existe otro camino para gravar legalmente dichas ganancias. Otra interpretación es violatoria del principio de legalidad que consagra el artículo $139^{\circ}$ de la Constitución y que recoge la norma IV del Título Preliminar del Código Tributario, e infringiría la norma IX de dicho Título.

\section{2) Rentas de fuente peruana}

La legislación peruana del impuesto a la renta denomina " $\mathrm{La}$ Base Jurisdiccional del Impuesto" al Capítulo Il del TUO. Según el artículo $6^{\circ}$, se presentan tres situaciones: a) para los contribuyentes no domiciliados, el impuesto recae únicamente sobre las rentas gravadas que son de fuente peruana, a cuyo efecto los artículos $9^{\circ}$ al $12^{\circ}$ tienen como misión señalar en forma expresa cuales son las rentas que, estando gravadas por el Capítulo I, califican como rentas de fuente peruana; b) todas las sucursales, las agencias y los establecimientos permanentes de contribuyentes no domiciliados en 
el país, para efectos del impuesto a la renta peruano tienen la calidad de domiciliados en el país conforme a la regla del inciso e) del artículo $7^{\circ}$ del TUO y tributan únicamente sobre rentas de fuente peruana, independizándose de sus dueños o casas matrices que conservan la condición de no domiciliados; c) los demás contribuyentes domiciliados en el país, quedan sujetos al impuesto sobre la totalidad de las rentas gravadas que obtengan, esto es sobre rentas de fuente mundial (rentas de fuente peruana y rentas de fuente extranjera).

Interesa exclusivamente el caso de las personas jurídicas no domiciliadas en el país, que no tienen en él ningún tipo de establecimiento permanente. Ellas son contribuyentes respecto del impuesto a la renta peruano, "sobre las rentas gravadas de fuente peruana". En esta última expresión, se incorporan dos conceptos: a) rentas gravadas, que son las contempladas en el Capítulo I del TUO; b) rentas de fuente peruana. Las rentas de fuente peruana tienen que estar calificadas como rentas gravadas. Dicho de otra manera, no pueden existir, legalmente, una renta de fuente peruana que no tenga la condición, según el Capítulo I del TUO, de renta gravada.

Esto surge muy claramente de lo dispuesto en el segundo párrafo del artículo $6^{\circ}$ del TUO y de la estructura del impuesto a la renta peruano. No se ve cómo sería posible, ni bajo qué argumentos, sostener una cosa distinta. Cuando se desee incorporar nuevos ingresos como rentas gravadas, la incorporación debe constar en el Capítulo I del TUO.

Ahora bien, las rentas de fuentes peruana están expresamente consignadas en el Capítulo II del TUO y, en concreto, en los artículos $9^{\circ}$ al $12^{\circ}$, haciendo una referencia este último al artículo $51^{\circ}$ para el solo efecto de determinar la renta neta tratándose de actividades que se desarrollan parte en el pais y parte en el extranjero. Por la vía del artículo $51^{\circ}$ no se pueden establecer nuevas rentas de fuente peruana. En consecuencia, basta analizar los artículos $9^{\circ}$ al $12^{\circ}$.

El artículo $9^{\circ}$ contiene cuatro tipos de rentas de fuente peruana. En su inciso a) incluye a las rentas producidas por predios situados en el territorio de la República, mostrando la existencia 
del vínculo territorial que es lo que califica a una renta como de fuente nacional. La fuente generadora de la renta se encuentra en el territorio nacional.

El inciso b) del artículo $9^{\circ}$, modificado por el Decreto Legislativo $\mathrm{N}^{\circ} 399$, se refiere a las rentas producidas por capitales, bienes o derechos (incluidas las regalías) situados físicamente o colocados o utilizados económicamente en el país. Al igual que en el caso anterior, la fuente generadora de la renta se encuentra físicamente situada en el territorio peruano o está colocada o utilizada económicamente en el Perú. Dicho inciso se basa en la Ley argentina $N^{\circ} 11682$, siendo así que su texto fué sustituido por el artículo $5^{\circ}$ de la Ley argentina $N^{\circ} 20628$, promulgada el 29 de diciembre de 1973 y publicada el 31 del mismo mes y año. Esta ley estableció el impuesto a las ganancias. afectando únicamente a las ganancias de fuente argentina, lo que lo diferencia del impuesto a la renta peruano. Pues bien, el artículo $5^{\circ}$ de la Ley 20628 estableció que "En general, y sin perjuicio de las disposiciones especiales de los artículos siguientes, son ga nancias de fuente argentina aquellas que provienen de bienes situados, colocados o utilizados económicamente en la República,. ..". Giuliani Fonrouge (6), al comentar esta Ley expresa que su texto consagra el principio de territorialidad o de la fuente como criterio de atribución de la ganancia o ingreso, agregando que dicho criterio es el único aceptable por cuanto la potestad tributaria tiene su fundamento en la soberanía ejercida allí donde la riqueza se integra en el conglomerado económico-social. También señala Giuliani Fonrouge (7) "que las cosas o los capitales pueden estar situados, colocados o utilizados en un lugar, pero los derechos no, porque son bienes incorpóreos o inmateriales, y aquellos conceptos parecieran referirse a una relación de ubicación en el espacio que sólo pueden tener los objetos materiales o cosas (arts. 2312 y 2313 , Cód. Civ.); los derechos se generan en un lugar pero no se sitúan, ni se colocan o utilizan en un lugar".

E1 impuesto argentino de la Ley 20628 se caracteriza además porque integra, dentro del concepto de ganancia o de renta grava-

(6) GIULIANI FONROUGE, Carlos M. y NAVARRINE, Susana, Impuesto a las Ganancias (Ediciones Depalma, Buenos Aires, 1976).

(7) GIULIANI FONROUGE y NAVARRINE, op. cit. 
da, los ingresos que constituyen renta según la teoria del réditoproducto y las ganancias que provienen de la enajenación de bicnes. Vale decir que grava el beneficio-renta y el beneficio-capital. para conferir a la ley ". . las características de simplicidad y fácil interpretación que es uno de los objetivos perseguidos", conforme cita Giuliani Fonrouge (8) al referirse al mensaje dado por el Poder Ejecutivo con motivo de la promulgación de la Ley 20628. Es cierto que la Ley 20628 ha sufrido diversas modificaciones, como se puede constatar en la obra "Impuestos Nacionales" (9), pero ellas han precisado estas dos características: a) únicamente se gravan las rentas de fuente argentina; b) son rentas gravadas no solamente las que responden al concepto de la teoría del rédito-producto sino también los rendimientos, rentas, beneficios o enriquecimientos que no respondan a tal concepto. bajo el cumplimiento de determinados supuestos, y los beneficios obtenidos por la enajenación de bienes muebles amortizables cualquiera que fuere el sujeto que los obtenga.

En todo caso, las ganancias obtenidas por personas juridicas no domiciliadas, como consecuencia de haber vendido acciones de su propiedad que han sido emitidas por sociedades constituidas en el país, no califican como rentas de fuente peruana bajo los alcances de inciso b) del artículo $9^{\circ}$ del TUO, cuyo texto fue tomado de una ley argentina que ya está modificada, lo que es preciso tener en cuenta, así como las especiales características del impuesto argentino a las ganancias, para su cabal interpretación.

El inciso e) del artículo $9^{\circ}$ del TUO califica como rentas de fuente peruana, a las originadas en el trabajo personal o en actividades civiles, comerciales o de cualquier indole, que se lleven a cabo en territorio nacional. Para la calificación de la renta como de fuente peruana, es imprescindible que el trabajo o la actividad generadores de renta se realicen en el territorio peruano. No es éste el caso de las ganancias a que se contrae el presente trabajo, porque ellas no provienen del trabajo personal ni de actividades realizadas en el pais, siendo usual que las acciones sean vendidas en el extranjero.

(8) GIULIANI FONROUGE y NAVARRINE, op. cit.

(9) ATCHABAHIAN, Adolfo, Impuestos Nacionales (Edición Extraordinaria de Derecho Fiscal, Arindo S.A., Buenos Aires, 1984). 
En cambio, la situación que nos interesa está contenida en el inciso d) del artículo $9^{\circ}$ del TUO, que considera rentas de fuente peruana "las obtenidas por la enajenación de acciones o participaciones representativas del capital de empresas o sociedades constituidas en el país". Para el análisis de este inciso vamos a prescindir, por no ser materia del presente trabajo, el caso de enajenación de participaciones representativas del capital de empresas al caso de enajenación de "acciones" representativas del capital de tales sociedades. Nuevamente es preciso recordar que estas rentas de fuente peruana tienen que haber sido consideradas previamente, por el Capítulo I del TUO, como rentas gravadas. Para el caso de personas jurídicas no domiciliadas en el país que obtienen ganancias por la venta de acciones de su propiedad, emitidas por sociedades constituidas en el Perú, y que no poseen en el país establecimientos permanentes, dichas ganancias, como se ha visto en el punto 1 de este trabajo, sólo son rentas gravadas en el caso del numeral 3 del inciso b) del artículo $3^{\circ}$ y en el caso del inciso c) del artículo $3^{\circ}$ del TUO. En ningún otro caso tales ganancias son rentas gravadas. Por lo tanto, el inciso d) del artículo $9^{\circ}$ del TUO sólo es de aplicación, cuando la ganancia es obtenida por personas jurídicas no domiciliadas y proviene de una operación de venta, en las siguientes dos hipótesis: a) cuando las acciones vendidas fueron adquiridas por la persona jurídica no domiciliada, en pago de operaciones habituales o para cancelar créditos provenientes de las mismas: b) cuando la persona jurídica no domiciliada en el pa is es habitual en las operaciones de venta de acciones.

Tiene pues una aplicación concreta el inciso d) del artículo $9^{\circ}$. Pero, cuando la ganancia es obtenida por la persona juridica no domiciliada, como consecuencia de la venta de acciones emitidas por sociedades constituidas en el país, se restringe a las dos hipótesis que han sido mencionadas en el párrafo anterior, si dicha persona no tiene en el Perú un establecimiento permanente.

En los demás artículos que califican una renta como de fuente peruana, no existe texto alguno que pudiera involucrar a las ganancias materia de análisis. En efecto, en el articulo $10^{\circ}$ del TUO, modificado por el Decreto Legislativo $\mathrm{N}^{\circ} 399$, se tipifica como rentas de fuente peruana a los intereses, comisiones, primas y toda suma adicional al interés pactado por préstamos, créditos o, en general. cualquier capital colocado o utilizado económicamente en 
el país; a los intereses de obligaciones, siempre que la entidad emisora haya sido constituida en el pais y cualquiera sea el lugar donde se realice la emisión, o el lugar de ubicación de los bienes afectados en garantía; los sueldos y cualquier tipo de remuneración que empresas domiciliadas en el país paguen o abonen a miembros de sus consejos $u$ órganos administrativos que actúen en el exterior; $\mathrm{y}$ los hónorarios o remuneraciones otorgadas por el Sector Público Nacional a personas que desempeñen en el extranjero funciones de representación o cargos oficiales.

El artículo $11^{\circ}$ del TUO comprende a las rentas del exportador, provenientes de la exportación de bienes producidos, manufacturados o comprados en el país. Y el artículo $12^{\circ}$ del TUO, en la parte que nos interesa, califica como rentas de fuente peruana a parte de las que obtienen contribuyentes domiciliados en el exterior, a raíz de actividades que se lleven a cabo parte en el país y parte en el extranjero.

\section{3) Jurisprudencia aplicable al régimen anterior}

Conviene comentar brevemente el contenido de tres resoluciones expedidas por el Tribunal Fiscal y que han recaído en el régimen anterior del impuesto a la renta, constituido por el Decreto Supremo $N^{\circ}$ 287-68-HC, promulgado por el Poder Ejecutivo al amparo de las facuitades extraordinarias que le fueron concedidas por la Ley $\mathrm{N}^{\circ} 17044$.

Dichas resoluciones llevan los números 8342,11617 y 15311.

La resolución del Tribunal Fiscal $\mathrm{N}^{\circ} 8342$ de 7 de mayo de 1973 , basándose en el numeral 6 del inciso a) del artículo $3^{\circ}$ del Decreto Supremo 287-68-HC, estableció que estaban afectas al impuesto a la renta las ganancias obtenidas en el pa ís, en las ventas de bienes de cualquier naturaleza que constituyan activo de empresas o sociedades que desarrollan actividades comprendidas en el inciso a) del artículo $27^{\circ}$ del mismo Decreto. En consecuencia, se gravó la ganancia obtenida por una persona jurídica no domiciliada en el país en la venta de acciones de su propiedad, emitidas por una sociedad anónima constituida en el país, considerando como materia imponible la diferencia entre el precio de venta de las acciones y su 
valor nominal. Se argumentó por el Tribunal Fiscal que el inciso a) del artículo $27^{\circ}$ no excluia a las sociedades establecidas en el extranjero, por no existir norma explícita que así lo declare $y$, al contrario, porque la empresa radicada en el exterior es sujeto pasivo de la obligación tributaria como dispone el inciso f) del artículo $14^{\circ}$ del referido Decreto.

En el dictamen que sustenta la mencionada resolución, se dice textualmente, al comentar los alcances del numeral 6 del inciso a) del artículo $3^{\circ}$ del Decreto, que "No es preciso que esas actividades sean desarrolladas en el país, puesto que si tal fuera la intención la disposición carecería de sentido en atención a que estaría sujeta al impuesto a la renta que esa actividad produce sin que fuera necesario gravar especialmente los resultados provenientes de la venta de bienes en el art. $3^{\circ}$ ".

Hay que situarse en el contexto del Decreto Supremo No 287 68-HC. Este, al igual que en el actual régimen del impuesto a la renta, contenía en su primer capítulo la relación de ingresos que constituían rentas gravadas, acogiendo la teoría del rédito-producto y afectando otros ingresos que no eran renta según esa teoria; dentro de las rentas gravadas se incluia las ganancias provenientes de la enajenación de bienes de cualquier naturaleza que constituyan activo de empresas o sociedades que desarrollan actividades comprendidas en el inciso a) del artículo $27^{\circ}$ del citado Decreto. El argumento esgrimido por el Vocal Informante, doctor M. Antonio Zárate Polo, mencionado en el párrafo anterior, llevaría a concluir que el numeral 6 del inciso a) del artículo $3^{\circ}$ sólo estaría refiriéndose a enajenaciones efectuadas por personas no domiciliadas, pues es su concepto que en el caso de personas domiciliadas que desarrollan actividades generadoras de rentas de tercera categoría, toda la renta que se produce está gravada.

En mi opinión, el Tribunal Fiscal no alcanzó a percibir cuál es la verdadera estructura del impuesto a la renta creado por el Decreto Supremo $N^{\circ}$ 287-68-HC, que en esencia es igual al impuesto actual. No percibió el Tribunal que existe el citado numeral 6 del inciso b) del artículo $2^{\circ}$, porque las ganancias provenientes de la enajenación de bienes no son rentas según la teoría del rédito-producto $\mathrm{y}$, en concordancia con lo expuesto en el artículo $1^{\circ}$ del Decreto Supremo $\mathrm{N}^{\circ} 287-68-\mathrm{HC}$, para quedar gravadas tenían que 
quedar expresamente mencionadas en los artículos $2^{\circ}$ o $3^{\circ}$. Equivocadamente el Tribunal asumió que bastaba desarrollar una actividad que genera rentas de tercera categoría, para que cualquier ganancia obtenida en dicha actividad quedara gravada con el impuesto, como si el Decreto referido hubiera tomado como concepto de "renta gravada" el de la teoría del incremento patrimonial neto o del rédito-ingreso, que nunca ha sido aplicado en el Perú.

Como en el régimen actual, el Decreto Supremo $N^{\circ} 287$ 68-HC gravaba a las personas no domiciliadas únicamente sobre las rentas de fuente peruana, a condición de que éstas previamente, en el Capítulo I, hubieran sido calificadas como rentas gravadas.

Tratándose de ganancias obtenidas en la venta de acciones por personas jurídicas no domiciliadas, el Tribunal Fiscal tenia que demostrar las siguientes dos cosas: a) que tales ganancias eran rentas gravadas, según las disposiciones contenidas en el Capítulo I del Título 1 del Decreto, por ser éstas las únicas normas pertinentes: b) que esas rentas gravadas estaban calificadas expresamente como rentas de fuente peruana, de acuerdo a lo dispuesto en los artículos $10^{\circ}$ al $13^{\circ}$ del Decreto, por cuanto las personas jurídicas no domiciliadas estaban afectas al impuesto únicamente sobre sus rentas de fuente peruana. Sin embargo, nada de eso demostró el Tribunal Fiscal en la resolución que estamos comentando. Extraña, sobremanera, que el Tribunal no hiciera la más mínima referencia a rentas de fuente peruana y confundiera, totalmente, el concepto de renta acogido por la legislación peruana.

Es bueno expresar que en el régimen actual el numeral 6) del inciso b) del artículo $3^{\circ}$ del TUO, se diferencia radicalmente del numeral 6 del inciso a) del artículo $3^{\circ}$ del Decreto Supremo $N^{\circ}$ 287-68-HC, en que el primero excluye, en forma clara e inequívoca, a las ganancias provenientes de la enajenación de bienes del activo fijo de propiedad de personas jurídicas no domiciliadas, sin establecimiento permanente en el país, en tanto que el segundo no hace tal exclusión, razón por la cual el Tribunal podría haber argumentado que constituía renta gravada, según este último numeral, toda ganancia obtenida en la venta de acciones emitidas por sociedades constituidas en el pais que fueran activo de una empresa domiciliada o no. Empero, tendría, a continuación de eso, que haber demostrado que esa renta gravada estaba calificada como renta de 
fuente peruana, lo que no surge de las disposiciones pertinentes contenidas en los artículos $10^{\circ}$ al $13^{\circ}$ del Decreto antes referido.

La resolución No 11617 de 16 de junio de 1976, ratificó el criterio expuesto en la resolución $N^{0} 8342$, agregando dos nuevos argumentos: a) que la ganancia en la venta de acciones estaba contemplada en el inciso b) del artículo $10^{\circ}$ del Decreto, con lo que tácitamente reconocía en esa ganancia una renta de fuente peruana, aún cuando es discutible la aplicación de dicho inciso; b) que no era aceptable el documento exhibido por el recurrente, a través del cual trató de probar que debia tomarse como costo computable, para determinar el monto de la ganancia, el costo de adquisición de las acciones que fueron vendidas y no el valor nominal de las mismas, ratificándose el Tribunal en considerar como costo computable dicho valor nominal. Es anecdótico que el Vocal informante calificara como "ingenioso" un argumento esgrimido por la empresa recurrente, en virtud del cual ésta trataba de demostrar que, siendo el contribuyente no domiciliado, se tenía que acreditar que la ganancia estaba calificada como renta de fuente peruana. No era pues un argumento ingenioso, sino la pura invocación de las normas vigentes, que el Tribunal tampoco pareció percibir con claridad, y en su verdadera dimensión, en su resolución $\mathrm{N}^{\circ} 11617$.

Finalmente, en la resolución $\mathrm{N}^{\circ} 15311$ de $1^{\circ}$ de agosto de 1979, el Tribunal Fiscal ratificó la jurisprudencia emanada de la resolución $\mathrm{N}^{\circ} 8342$ y confirmada por la resolución $\mathrm{N}^{\circ} \quad 1617$, aún cuando reconoció de manera explícita que la ganancia está dada por la diferencia entre el precio de venta de las acciones y "el costo establecido de las inversiones", constituyendo el caso una situación especial porque la ganancia provenia de la transferencia de "acciones y derechos".

\section{4) Conclusiones}

El actual régimen del impuesto a la renta en el Perú, contempla únicamente en su Capítulo I los ingresos que constituyen rentas gravadas. A este efecto, clasifica las rentas gravadas en dos grupos: a) las que responden al concepto de la teoría del rédito-producto; b) las que no responden a ese concepto, pero están expresamente consideradas como rentas gravadas por los artículos $2^{\circ}$ y $3^{\circ}$ 
del Capítulo I, incluyéndose entre éstas a las ganancias de capital que provienen, bajo ciertas condiciones, de la enajenación de bienes. Los artículos $4^{\circ}$ y $5^{\circ}$, que son los últimos del Capítulo I, no tienen por objeto gravar nuevos ingresos sino establecer presunciones de habitualidad, en el caso del artículo $4^{\circ}$, y definir el concepto de enajenación, en el caso del artículo $5^{\circ}$.

En tal virtud, el Capítulo I del TUO define, como se señala en la denominación de dicho capítulo, el campo de aplicación del tributo, o el objeto del mismo. Lo que no está incluido en ese capítulo, no es renta gravada con el tributo. Si se quiere, recogiendo lo que al respecto dice De la Garza (10), en el citado capítulo está el aspecto material o fáctico del hecho imponible.

Cuando una persona jurídica no domiciliada no tiene un establecimiento permanente en el Perú y obtiene una ganancia por la venta de acciones de su propiedad que han sido emitidas por sociedades constituidas en el Perú (sociedades anónimas o sociedades en comandita por acciones), tal ganancia sólo sería renta gravada en las hipótesis contempladas en el numeral 3 del inciso b) del artículo $3^{\circ} \mathrm{del}$ TUO y en el inciso c) de dicho artículo.

El numeral 3 del inciso b) del artículo $3^{\circ}$ del TUO considera como renta gravada el resultado proveniente de la enajenación de bienes adquiridos en pago de operaciones habituales o para cancelar créditos provenientes de las mismas. El inciso c) del artículo $3^{\circ}$ del TUO califica como renta gravada el resultado de la venta, cambio o disposición habitual de bienes. En a mbos casos, en el concepto "bienes" se incluyen las acciones. Dentro de los conceptos "enajenación" y "disposición" se incluye la venta de acciones.

Las personas jurídicas no domiciliadas, en virtud de la norma contenida en el artículo $6^{\circ}$ del TUO, únicamente tributan sobre rentas de fuente peruana, presuponiendo este último concepto que la renta esté gravada a tenor del Capítulo I del TUO. El inciso d) del artículo $9^{\circ}$ del TUO, expresamente tipifica como rentas de fuente peruana las obtenidas por la enajenación de acciones del capital de sociedades constituidas en el país, aplicándose esta norma,

(10) DE LA GARZA, Sergio Francisco, Derecho Financiero Mexicano (Editorial Porrúa S.A., México, 1983). 
exclusivamente, a las ganancias obtenidas en la enajenación de tales acciones, y por lo tanto en la venta y otros actos de disposición de las mismas, cuando siendo ellas de propiedad de las personas jurídicas no domiciliadas tales ganancias están gravadas por el numeral 3 del inciso b) del artículo $3^{\circ}$ del TUO o por el inciso c) de dicho artículo $3^{\circ}$.

Para llegar a las conclusiones antes expuestas, se ha trabajado sobre la base de ciertos supuestos que deben darse acumulativamente y que son los siguientes: a) existe una ganancia; b) ésta debe haber sido obtenida por una persona jurídica no domiciliada en el país; c) dicha persona no tiene ningún establecimiento permanente en el Perú; d) la ganancia proviene de la venta de acciones emitidas por sociedades anónimas o por sociedades en comandita por acciones; e) las sociedades emisoras de las acciones están constituidas en el país: f) la persona jurídica que obtiene la ganancia es, obviamente, propietaria de las acciones que está vendiendo.

El presente trabajo no ha contemplado específicamente el caso de ganancias obtenidas por operaciones de enajenación que no sean ventas.

San Isidro, 26 de junio de 1987 